\title{
Espaços ficcionalizados em Desterro, de Luis S. Krausz: um ensaio em geografia literária
}

Georg Wink

Este artigo entende-se como um ensaio em geografia literária. Com essa declaração introdutória, queria chamar atenção para o caráter experimental da minha abordagem: trata-se, de fato, de uma tentativa de testar a aplicabilidade dos métodos de uma determinada vertente crítica, ainda incipiente e algo indefinida, que pode ser denominada como "geografia literária" (Piatti, 2008) - outros termos em uso são "geografia da literatura" (Moretti, 1999) e "geocrítica" (Westphal, 2011). Dessa forma, a minha contribuição será uma continuação lógica das reflexões teórico-metodológicas sobre a "geografia literária", apresentadas em artigo anterior (Wink, 2015).

Queria antecipar que a "geografia literária" oferece uma aproximação bastante diferenciada à obra literária. Ela parte da premissa, algo óbvia, de que a maioria dos textos ficcionais pode ser localizada geograficamente, no que diz respeito ao cenário e enredo, sendo que essas localizações são concebidas de múltiplas maneiras, entre a imaginária e a realista. O método implica, bem resumidamente, analisar, através da produção de mapas, questões relevantes à relação entre texto e espaço, como as várias formas de referenciar espaços geográficos (indicar, suprimir, anonimizar, transformar) e as funções narrativas atribuídas aos espaços ficcionalizados.

$\mathrm{O}$ enfoque da minha contribuição, portanto, recai sobre a potencialidade e os limites da abordagem, pelo exemplo do romance contemporâneo Desterro: memórias em ruinas (2011), de Luis S. Krausz. Começarei com algumas breves observações sobre o autor e o livro para, em seguida, resumir, da maneira mais concisa possível, em que consiste a metodologia da "geografia literária", sobretudo para explicar os conceitos e termos. Depois, analisarei alguns dos espaços ficcionais criados pelo livro, com o suporte de alguns mapas analíticos, como é previsto pelo método. Na conclusão, discutirei em que aspectos essa análise contribuiu à interpretação do livro.

\footnotetext{
${ }^{1}$ Doutor em estudos aplicados de cultura e língua espanholas e portuguesas e professor da Universidade de Copenhague, Kobenhavn, Dinamarca. E-mail: zpj103@hum.ku.dk
} 


\section{Sobre o autor e o livro}

Desterro: memórias em ruínas é, primeiro, o relato de um flâneur que perambula por algumas ruas - bem escolhidas - de São Paulo e, segundo, de um errante, como observa Márcio Seligmann-Silva (2011, p. 145) no seu posfácio. Errante, porque busca, refazendo os itinerários da memória doída, entre as ruínas da história de sua família e dos amigos que compartilharam o mesmo destino, algo - talvez não uma resposta, mas algum alívio de sua angústia. $\mathrm{O}$ narrador, que, praticamente, convida a ser identificado com o autor, hoje professor de literatura hebraica e judaica na Universidade de São Paulo, é descendente de imigrantes judeus da Áustria e da Rússia. Tem de se mencionar que seus avós formaram parte daquele grupo de imigrantes que chegaram já no final dos anos 20, ou seja, que vivenciaram de outra forma a shoah, pela distância. ${ }^{2}$ Essa condição dá à versão ficcionalizada da história familiar um gosto picante, por exemplo, quando descreve, em detalhe, a quase inabalada confiança da família na superioridade da "cultura germânica", por exemplo, quando faz menção do caso de um conhecido da família que, na sua casa em Campos do Jordão, escuta toda noite, sagradamente, óperas de Wagner (Krausz, 2011, p. 69), ou ainda a convivência, surpreendentemente aproblemática, com nazistas alemães foragidos depois da guerra (Krausz, 2011, p. 118).

A trama, que é basicamente a reconstrução narrativa e o comentário dos múltiplos pedaços da memória compartilhada, desenvolve-se em vários planos.

1) O passeio do narrador, revisitando os lugares do passado, como na frase: "Eu ando desorientado pelas ruas curvas, ainda silenciosas, ainda verdes, do alto do Sumaré" (Krausz, 2011, p. 12).

2) A reprodução, bastante objetiva, da história familiar do narrador e do seu contexto: "Meu avô recebeu o nome do Kaiser Wilhelm, para comemorar a amizade entre a Áustria e a Alemanha" (Krausz, 2011, p. 122, grifo no original).

3) A descrição do próprio trabalho de memória do narrador, enquanto adulto, como no exemplo: "Ainda naquela semana me convencera de que talvez um caco da minha Jerusalém celeste

\footnotetext{
${ }^{2}$ Entrevista informal com Luis S. Krausz, realizada pelo autor no dia 14 de março de 2013, em Berlim.
} 
particular estivesse naquele tapete, e me apressei em levá-lo à casa de uma empregada de nossa consertadora armênia de tapetes orientais [...]" (Krausz, 2011, p. 19). Esse nível narrativo inclui também a fuçação de um armário, depositado no subsolo de um apartamento do narrador, repleto de objetos herdados por sua vez, repletos de memória (Krausz, 2011, p. 20), bem como o trabalho de campo, realizado pelo narrador para o Museu Judaico de Berlim, através de entrevistas com judeus austríacos e alemães e seus descendentes que tinham emigrado para São Paulo (Krausz, 2011, p. 36).

4) A retrospectiva sobre as viagens do narrador à Europa, em busca do prometido "Primeiro Mundo", como nas frases: "Por décadas eu percorri os quadrantes do que era, então, chamado de 'Primeiro Mundo', em busca do lugar com o qual os meus avós sonhavam - aquele lugar mais elevado que os outros lugares, de onde fomos expulsos, e que haveria de nos ser restituído" (Krausz, 2011, p. 27). Algo curioso - e uma expressão da ironia sutil do autor - é que o narrador busca o glamour do primeiro mundo justamente na cidade proletária Duisburg, que nos anos 1980 era paradigmática para o declínio da época industrial e o crescente desemprego.

5) As próprias lembranças da infância do narrador, por exemplo: "A família se reunia à volta daquela mesma mesa, para tomar uísque com Salzstangerln" (Krausz, 2011, p. 18, grifo no original).

\section{A metodologia}

A distinção destes planos é de suma relevância para a análise a seguir, já que, obviamente, cada plano implica diferentes relações possíveis entre narração/narrador e espaço narrado. No texto, em sua totalidade, constam em torno de 50 espaços narrados com caraterísticas próprias. Considerando as perguntas condutoras - a) Qual é a relação do espaço narrado com o espaço "real" ?; b) Como o espaço narrado é organizado?; e c) Qual é a função dessa organização em relação às estratégias narrativas? - priorizei, entre as muitas ferramentas disponibilizadas pela metodologia (Wink, 2015), as seguintes quatro 
categorias de parâmetros, oriundas da "geografia literária" em suas várias vertentes, na análise de cada espaço.

1) A referencialidade direta versus indireta do espaço narrado.

a) Espaço importado: real e citado pelo topônimo, por exemplo, na frase: "É mais uma daquelas manhãs de São Paulo" (Krausz, 2011, p. 9).

b) Espaço anonimizado, embora às vezes reconhecível, como a menção feita ao parque de diversões Hopi Hari (Krausz, 2011, p. 21).

c) Espaço transposto, "real", mas com nomes alterado, como o bairro chamado "Nova São Paulo" (Krausz, 2011, p. 20), que se estende além do rio Tietê.

d) Espaço sintetizado, uma fusão de vários lugares, como o bairro "Nova São Paulo" com o lugar mítico Atlântida e a cidade norte-americana de Atlanta (Krausz, 2011, p. 21) ou o Largo da Batata e a Praça Alexanderplatz, em Berlim.

e) Espaço histórico e já não existente, como no capítulo 5, "Nosso mar", o sítio bucólico da represa de Guarapiranga e do canal de Jurubatuba, que leva ao rio Pinheiros, ficcionalizado como "o nosso mar da Galileia, o nosso Zürichsee” (Krausz, 2011, p. 43). O mesmo rio Pinheiros, que, como observa o narrador mais tarde, hoje é "nossa cloaca pública que, com a inauguração da Ponte Estaiada, se transformou em cartão-postal da nova cidade" (Krausz, 2011, p. 24-25).

2) A função atribuída ao espaço narrado e ao grau de elaboração ou aprofundamento.

a) Espaço apenas como "palco" para a ação, sem que esta dependa especificamente deste lugar escolhido.

b) Espaço como cenário paradigmático, de representatividade simbólica, e necessário ao argumento. 
c) Espaço como cenário sui generis, representado de forma aprofundada ou até com a intenção de exaustividade (como seria no caso da Dublin descrita por James Joyce).

d) Espaço como cenário intrinsecamente associado à história contada.

3) A relação do espaço narrado com a trama e os atores.

a) $\mathrm{O}$ espaço tem característica de zona de atuação dos protagonistas, como é o caso no passeio e no trabalho de memória do protagonista.

b) O espaço projetado pelos protagonistas (ou pela voz narrativa), sem que a ação se desenvolva concretamente nesse espaço, como nas lembranças do protagonista.

c) A presença de marcadores de espaço, não associados à atuação (inexistente no texto em questão, pois os espaços sempre demarcam fronteiras invisíveis que delimitam o raio de atuação).

d) $\mathrm{O}$ espaço como protagonista, seja físico-atuante, seja psíquico-poético, como na frase: "ao olhar para cima, os olhos perfuram o manto de fuligem que cobre toda a cidade, como um ser dotado de vontade própria, como um parasita insaciável" (Krausz, 2011, p. 9).

4) O grau de extensão, por exemplo, um quarto ou o mundo inteiro, e a fragmentação de espaços, a serem suplementados no ato da leitura. Há que observar aqui que os espaços em Desterro são claramente extensos e fragmentados, como mostra a frase que descreve o pensamento do narrador, em frente às galerias do Shopping Iguatemi: "parecia-me que levariam diretamente aos corredores do Jelmoli, na Bahnhofstraße de Zurique; para as escadas rolantes do KDW de Berlim onde, eu suspeitava, a era messiância já estava começando" (Krausz, 2011, p. 75). Essa característica pode ser ilustrada por uma visão geral dos espaços narrados incluídos num mapa-múndi: 


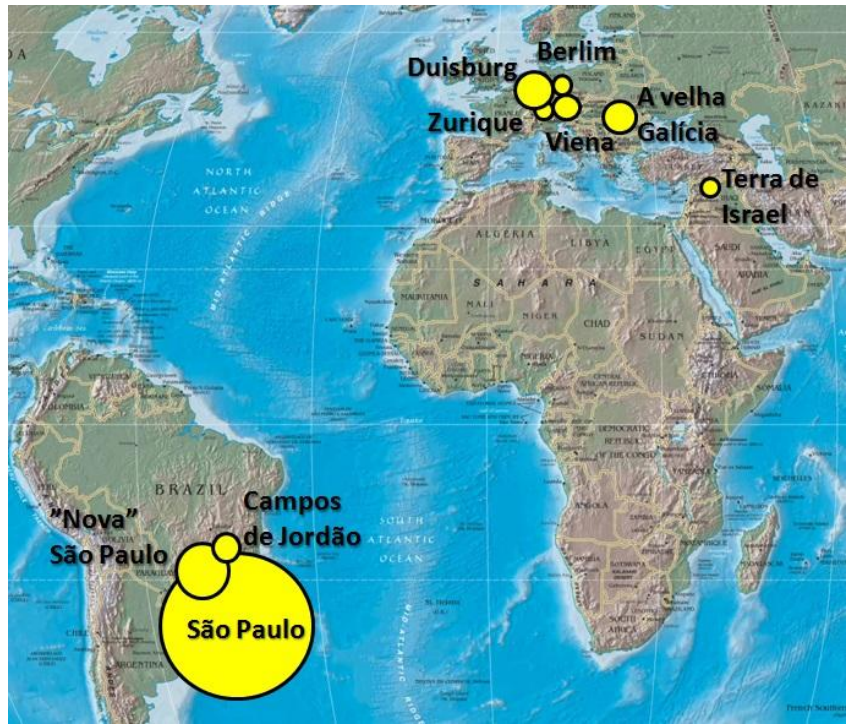

Figura 1 - A localização geográfica dos espaços narrados em Desterro (quanto maior o diâmetro, há mais referências ao lugar).

\section{Análise e interpretação}

Os resultados da análise, feita com base nesses parâmetros, foram muito extensos. Para a finalidade deste trabalho, que é de testar e demonstrar as possibilidades e os limites da aplicação da metodologia a um texto, resolvi não dar a mesma ênfase a todos os 50 lugares e tampouco a todos os parâmetros. Concentrar-me-ei em dois fenômenos mais relevantes e pertinentes, no que diz respeito às perguntas condutoras: primeiro, a referencialidade direta versus a indireta dos espaços; e, segundo, a relação dos espaços com a trama e os atores, ambos procedimentos analíticos em relação aos espaços narrados situados em São Paulo.

No que concerne à referencialidade direta versus a indireta, predominam, claramente, os lugares importados. O autor informa a maioria dos lugares com precisão, ou seja, providencia pelo menos a rua e, às vezes, o endereço completo, o que facilita o reencontro na geografia real. Isso é valido para os vários logradouros da família em São Paulo (nos bairros Alto do Sumaré, Vila Mariana, Brooklin Velho); para os logradouros dos seus informantes, os quais o protagonista visita durante a sua pesquisa para o Museu Judaico de Berlim (Rua da Consolação, edifício Mayrink, 
Higienópolis); e também para a sua moradia durante a sua estada na Alemanha (Rua Am Finkenacker 6, Duisburg). Seria, então, interessante indagar sobre as exceções da regra. $\mathrm{O}$ caso mais evidente é o do bairro "Nova São Paulo", lugar transposto e sintetizado, uma área difusa, com conotação claramente negativa, que se estende além do rio Tietê em direção ao poente, "na planície que ia até Jundiaí" (Krausz, 2011, p. 25). "Nova São Paulo" é caracterizada, pelo autor, como "terras malvistas, consideradas nocivas por causa dos pântanos" (Krausz, 2011, p. 25), nos quais surgira "um bairro novo, como que de um dia para o outro" (Krausz, 2011, p. 21), composto de "casarões erigidos às pressas, com o dinheiro fácil" (Krausz, 2011, p. 97). A oposição a esse espaço, o único ficcionalizado dessa forma, é - obviamente - a "Velha São Paulo", embora não se use o adjetivo. Antigamente lugar privilegiado, mas ora quase devorado pelos emergentes novos ricos e, ao mesmo tempo, pela "ralé": trata-se dos bairros nobres Alto do Sumaré, Santa Cecília, Higienópolis, Vila Mariana, Alto da Boa Vista, Jardins, Velho Brooklin (além de Campos de Jordão), com seus apartamentos e suas casas "sempre obscurecidas por cortinas grossas que deixavam de fora a luz dura dos trópicos e estabeleciam ali um minúsculo reinado de penumbras europeias" (Krausz, 2011, p. 75).

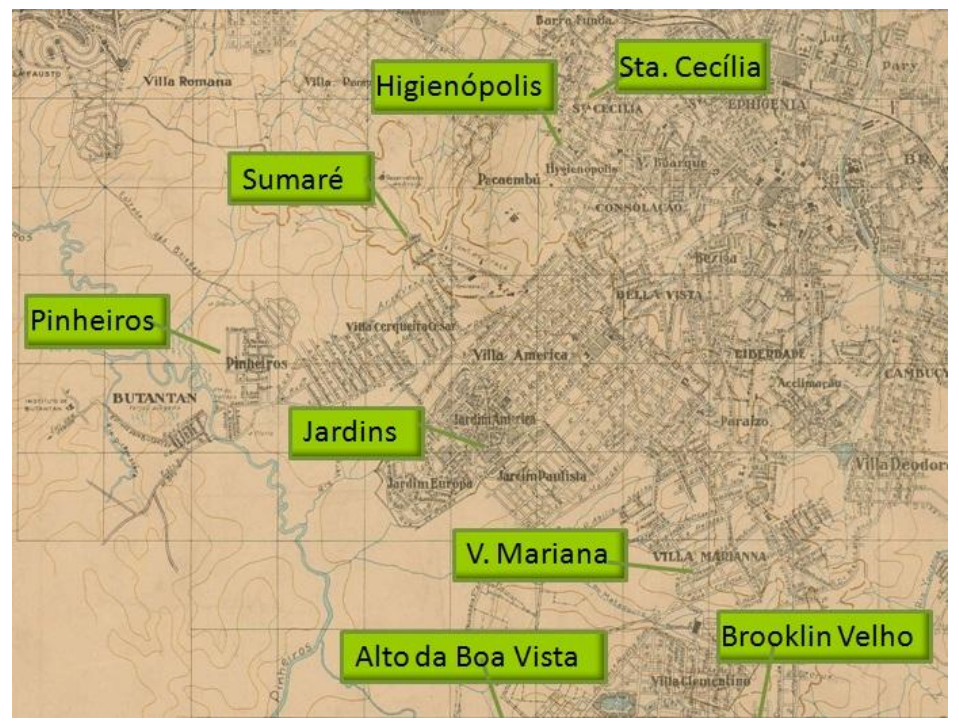

Figura 2 - Mapa original de São Paulo, de 1924, com indicação dos nomes dos novos bairros nobres, mencionados em Desterro. 
A "Velha São Paulo" é desenhada como um mundo maravilhoso em extinção, criado pelos imigrantes europeus com patrimônio ou uma formação que permitia adquiri-lo em curto prazo, no qual o narrador foi socializado:

perfumes: o dos jasmins e dos pinheiros; o dos lírios, agapantos e azaleias, iguais aos que brilhavam nos jardins dos meus avós, no jardim da nossa Tante Anna, cercado de cedrinho: um pedaço de boa sorte esquecido na cidade, como um capricho da história. Era daqueles jardins que nós olhávamos, com desdém e piedade, para a vida suarenta das ruas (Krausz, 2011, p. 12, grifo no original).

No que concerne ao segundo grupo de parâmetros, a relação dos espaços narrados com a trama e os atores, especialmente a zona de atuação e o espaço projetado, o motivo do meu foco é que as definições e a distinção se revelaram como insuficientes para capturar uma dimensão relevante do texto. O narrador é um flâneur, no sentido próprio de ambulante, apenas no Alto do Sumaré. Dois pontos marcam os limites dessa zona: o mirante da Rua Corumbá, virado para o nascente, do qual o narrador avista Pacaembu, a Avenida Paulista, o Conjunto Nacional; mas também imagina, atrás do horizonte, a Europa e o próprio passado. Lá também se lembra da sua espera, em vão, pelo aparecimento do cometa Halley, em 1986, desejado como uma redenção. A poucos passos encontra-se o outro mirante, no fim da Rua Mococa, virado para o poente, cuja visão é bem outra: “à sua frente se estendia a desolação interminável da planície, a marcha infame em direção ao faroeste, aquelas terras inomináveis [...]" (Krausz, 2011, p. 33).

As oposições entre passado e futuro, sacro e profano, precioso e barato, aqui associadas aos pontos cardiais, são bastante claras e, sem dúvida, mereceriam uma interpretação à parte, numa análise que tenha outros objetivos. Mas, para a minha finalidade, prefiro levantar aqui uma outra pergunta: o que acontece aos pés do narrador, quando este desce da sua posição privilegiada? Isso é descrito numa passagem notável, que, pela definição, se enquadraria no espaço de atuação embora mostre, de forma sintomática, características de projeção: na Avenida Dr. Arnaldo, "na crista da cordilheira que dividia nossa cidade" (Krausz, 2011, p. 66), o flâneur embarca no ônibus Lapa R (hoje idêntico à linha 856-R), "em direção aos círculos cada vez mais baixos" (Krausz, 2011, p. 66). O flâneur - aliás, ainda será um flâneur? - olha, 
aflito, pelas janelas. O percurso a seguir lembra a descida aos infernos de Dante, com a Rua Cardeal Arcoverde como tobogã e o Largo da Batata como a cratera provocada pela queda de Lúcifer.

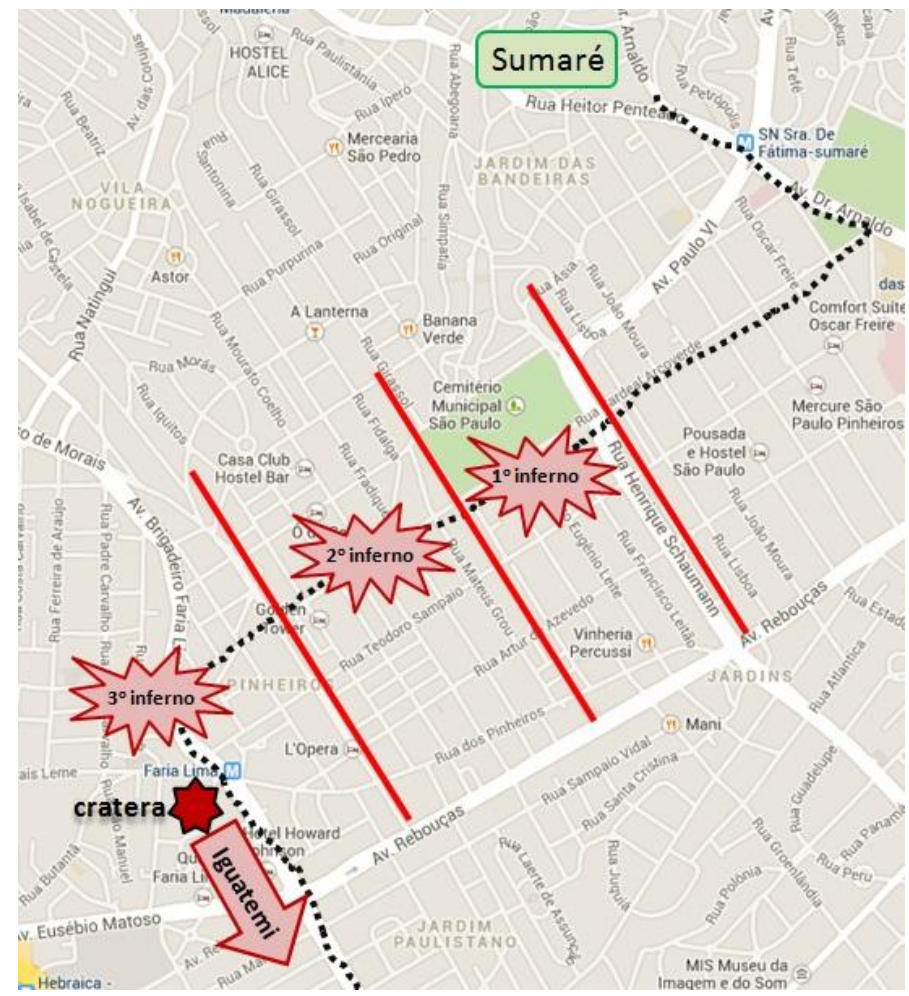

Figura 3 - Percurso de ônibus, análogo a uma descida aos infernos dantescos.

Enquanto o limbo (círculo 1 do inferno) é associado ao cemitério do Araçá (reservado, entre outros, aos que morreram pagãos), o primeiro inferno (círculos 2 a 4, reservados para pecados de ganância, luxúria, gula e similares) começa logo depois da Av. Henrique Schaumann, ou seja, o rio Aqueronte: “o semáforo apinhado de malabaristas, mendigos, inclusive uma mendiga obesa que decerto esbanjava todas as suas esmolas no McDonald's" (Krausz, 2011, p. 67). O segundo inferno (círculos 5 a 7, reservados para pecados de ira, violência, heresia e afins) é representado pelas "espeluncas e hotéis suspeitos" e "os bares que 
atraíam desocupados de todos os tipos, criminosos ocasionais" (Krausz, 2011), que caracterizam o próximo trecho da rua. O terceiro inferno (círculos 8 a 9, destino de infratores nos segmentos de fraude, traição etc.) começa depois de cruzar a Av. Pedroso de Moraes, quando o ônibus estremece "como um avião ao entrar em zona de turbulência [...] Las Vegas" (Krausz, 2011, p. 68). Quando o ônibus passa pelo Largo da Batata, lugar da cratera e ponte de partida dos micro-ônibus para a "Nova São Paulo" e termina a viagem no Shopping Iguatemi, "os furtos famélicos e os crimes comezinhos davam lugar às pompas e cerimônias, aos falsos afetos, aos gestos vazios, às verossimilhanças epidérmicas e às imagens evanescentes" (Krausz, 2011, p. 72).

O que é narrado aqui é uma experiência de alienação, vivenciada formalmente no espaço de atuação, mas sempre através do vidro de um veículo, como um filme. Por essas características duvido que ainda se trate de um flâneur, como aquele que passeia pelo Alto do Sumaré. (Talvez esteja na hora de definir um novo tipo de flâneur, aquele motorizado, que se situa numa cápsula em movimento e observa pelo recorte dos vidros, parecido - mas não necessariamente igual, pela visão também frontal dos para-brisas - com um passageiro de trem.) Metodologicamente, e para a nossa finalidade restrita, seria mais lógico associar esse espaço ao projetado.

Em Desterro, aparecem outros espaços que testemunham uma sensação de alienação, vivenciada a partir de um veículo, que, regularmente, se relacionam com alguma ação de afirmação da própria identidade. Podemos mencionar as "expedições" da família ao bairro Bom Retiro para comprar pão preto e trigo sarraceno, no capítulo 10 "Bom retiro, melhor retiro" (Krausz, 2011, p. 89 e seguintes). Bom Retiro foi o reduto dos judeus do Leste, tachados como culturalmente inferiores pela família. Como lembra o narrador, a viagem até lá se dá de carro, escutando música popular alemã, praticamente como antídoto.

Em outras situações, sempre pela janela do automóvel, o narrador, no caminho de volta da escola, avista prostitutas na Av. Lineu de Paula, e, no caminho de volta da sinagoga, travestis na Rua Joaquim Nabuco (Krausz, 2011, p. 131). Já adulto e em posse da carteira de habilitação, o narrador se dirige à rua Fidalgo em Parelheiros, bairro de classe baixa, para levar um precioso tapete oriental a uma consertadora. Na volta compra, "como um suvenir 
daquela viagem exótica", pelo preço de R\$ 2,19, um frango abatido como ração para o cachorro (Krausz, 2011, p. 19).

Nesses exemplos, temos que considerar que, por trás das colocações, deverá haver uma boa porção de autoironia por parte do autor, questionando a própria condição de representante da classe privilegiada. Mas vale a pena investigarmos como são apresentados esses "espaços exóticos", especialmente pela comparação de dois possíveis níveis de análise: um mais evidente, e até agora não contemplada aqui, visando ao trabalho de memória; a outra, privilegiada aqui, visando à representação do espaço urbano socialmente dividido de São Paulo.

O tema central do livro poderia ser resumido como a busca no passado familiar por uma identidade. Essa busca é condenada ao fracasso, porque, como o autor mostra bem através da sua ficção, o passado é sempre inatingível, a memória, sempre apenas uma construção. Essa mensagem está resumida na frase: “Eu ainda não imaginava que drüben [em alemão, "do outro lado"] era sempre do outro lado" (Krausz, 2011, p. 27). O que aparenta ser uma tautologia é a chave do livro, pois o uso da palavra alemã drüben condensa todo um discurso saudosista familiar, sobre um passado melhor, numa terra melhor. Os vários "do outro lados" e as respectivas divisas podem ser sistematizados num mapa da diáspora, a começar com o cativeiro babilônico, as migrações dentro da Europa (associadas à questão da assimilação) e o exílio no novo mundo. 


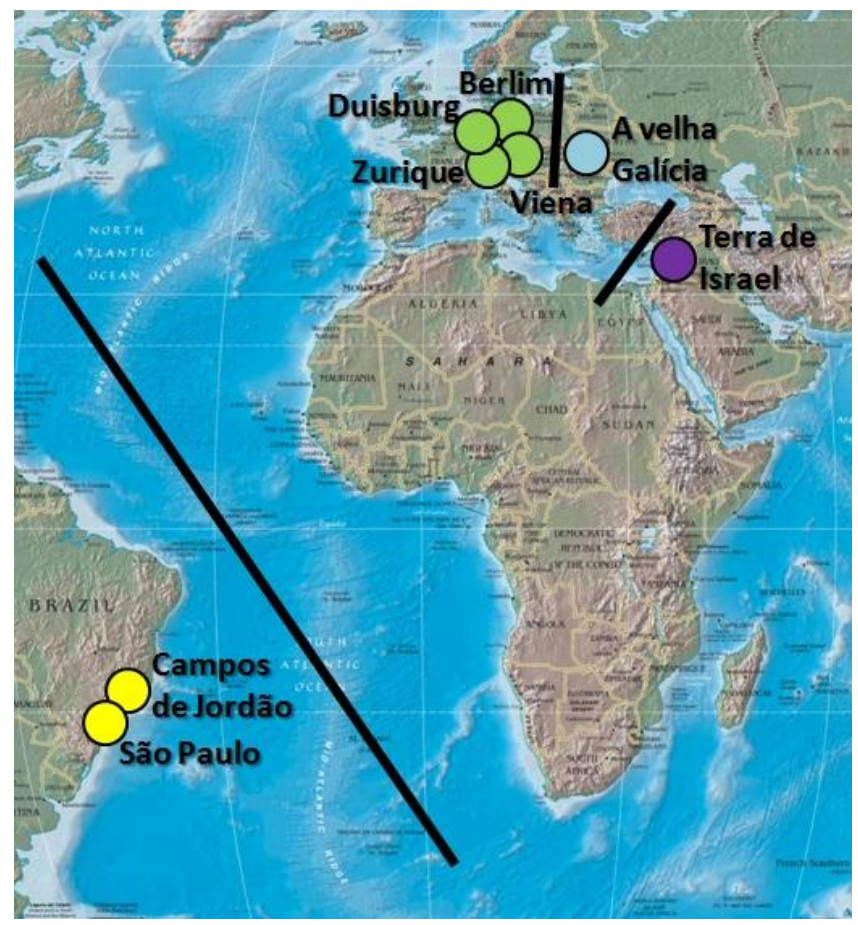

Figura 4 - Espaços "do outro lado" e as respectivas divisas.

Dessa forma, o livro veicula uma crítica, do ponto de vista da terceira geração, contra o discurso saudosista dos pais: não vale a pena agarrar-se à memória, já que sempre seriam desterrados. Seria melhor abdicar da memória, uma vez que o livro está escrito, ou seja, o trabalho de memória está concluído. Abdicar dela como do quadro que fora furtado a um amigo da família do narrador e, de repente, reapareceu no Museu Judaico de Berlim. Valeria a pena tentar reconquistá-lo, reivindicando os direitos de propriedade? $\mathrm{O}$ episódio que encerra o livro sugere que não. A perda, num nível simbólico (o quadro mostra "Judeus ao caminho da casa de orações"), poderia ter um efeito catártico: livrar o amigo "daquela origem infausta" (Krausz, 2011, p. 144). Porém, o que essa digressão do meu foco de análise tem a ver com a representação do espaço social?

Para metaforizar a divisão entre o aquém presente e o além passado, o autor recorre, frequentemente, aos elementos "rio" e "ponte". Constam do livro dois capítulos com o título "As pontes": ambos 
contêm o argumento central sobre a situação do desterro, do exílio, do viver sob a "fórmula mágica, nunca pronunciada" do como se: "Conversaram sobre livros alemães como se, e sobre viagens a estações termais na Alemanha como se, e organizavam viagens em grupo para fazerem as curas de águas em Karlsbad como se, e observaram as montanhas e o céu de Campos do Jordão como se" (Krausz, 2011, p. 103). Ora, o como se funciona como uma ponte imaginária (eis o porquê do título do capítulo) que, pela conexão, paradoxalmente mantém o individuo na situação de desterro. A consequência lógica, embora não explicitada pelo autor poderia ser: derrubem as pontes!

Se tentarmos agora criar um nexo entre os vários elementos analisados, a nomear, o trabalho de memória exposto, o espaço projetado da "Nova São Paulo", a descida de ônibus aos infernos e as várias excursões ao mundo exótico do povo, algo curioso se revela. A mesma metáfora da divisa e da ponte é usada, talvez de forma inconsciente, para delimitar os espaços sociais, de classe, como no caso da viagem exótica a Palheiros: "Para chegar ali cruzei rios e ferrovias" (Krausz, 2011, p. 19). Para ilustrar isso, é preciso outro mapa:

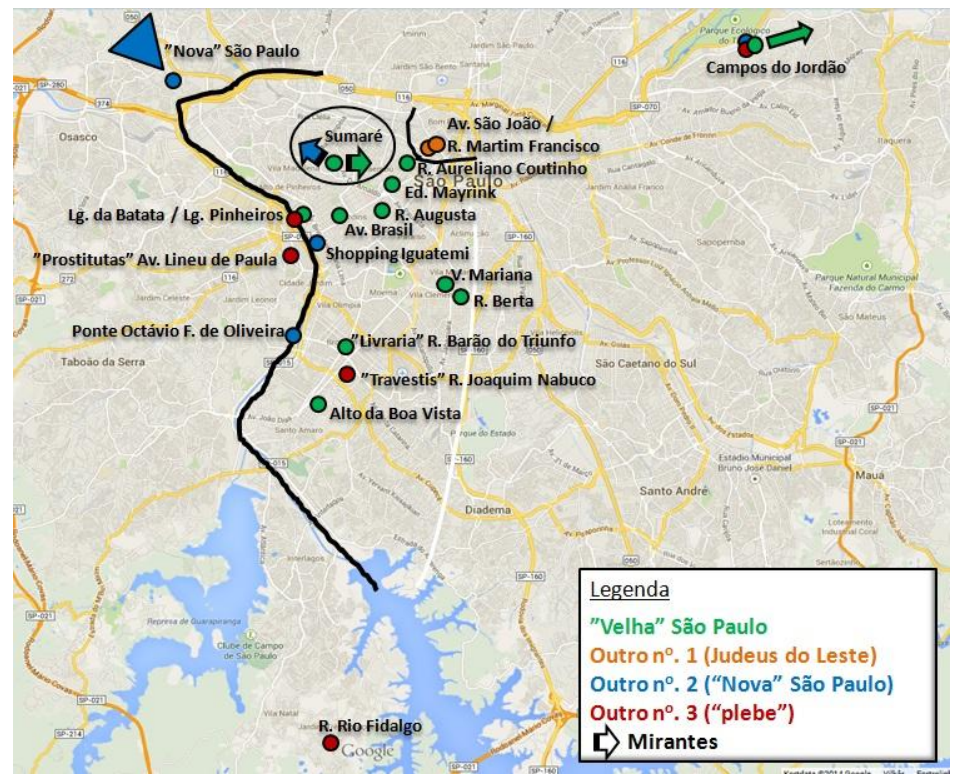

Figura 5 - Mapa dos espaços sociais e suas divisas, como desenhados pelo texto. 
Podemos ver, a partir do mapa, que a zona de atuação do protagonista é praticamente sitiada por várias ameaças de "outros". Primeiro, os Judeus do Leste, uma ameaça de porte menor e quase do passado (mesmo assim, o livro faz questão de mencionar a desvalorização de um apartamento pela presença de judeus russos barulhentos na vizinhança). Segundo, o bairro fictício da "Nova São Paulo", dos novos ricos, que, junto com, terceiro, a "plebe", ou seja, os velhos pobres, avançam pelos rios Tietê e Pinheiros em direção à fortaleza do Alto do Sumaré. As fronteiras são explícitas, no mapa indicadas em cor preta, mas também implícitas, em cor branca, como a fronteira que demarca os espaços "omitidos", nunca mencionados, que inclui todo o leste da cidade. Mas, sobretudo, as fronteiras estão em processo de desaparecimento, devido às invasões do outro lado do rio. Nessa perspectiva, uma frase-chave, que aparentemente se refere apenas ao trabalho de memória, à superação do trauma do desterro, talvez possa ser lida também num outro sentido: "As pontes sobre aquela água me davam muito medo. Ligavam, em sua arrogância, coisas que deveriam permanecer separadas pela água" (Krausz, 2011, p. 44). Nessa leitura, a frase iria expressar também o lamento de - honi soit qui mal y pense - uma perda de privilégios. Pelo menos a representação diferenciada dos lugares referenciados aparenta reproduzir essa atitude, independentemente da motivação subjacente. Podemos supor também que essas topografias literárias assimétricas, desenhadas pelo autor, são em boa parte fruto de uma geografia imaginada coletiva - e a afirmam como tal.

\section{Conclusão}

Para finalizar este ensaio experimental em geografia literária, coloca-se a pergunta: não se teria atingido este resultado através de qualquer aproximação metodológica ao texto? Responderia com um sim e não. Alguma sensação difusa sobre como os espaços são representados, o texto causaria, provavelmente, logo na primeira leitura, especialmente quando se chega ao percurso de ônibus, sendo esse o trecho que mais desperta para a questão. Contudo, sem o mapeamento que expõe as relações encobertas no texto - e lembremos que a produção de mapas é uma ferramenta analítica e não apenas uma ilustração -, talvez não tivesse ficado claro que o 
fenômeno não é apenas uma tendência, mas algo estrutural, sistematicamente produzido pelo texto, embora talvez não intencionalmente. Teria ficado claro que o texto constrói a tal "Nova São Paulo" como uma ameaça, mas provavelmente não como o bairro é construído: pela transposição e sintetização, ou seja, pelo desvio da regra de importação de lugares. Teria ficado claro que o narrador se sente alienado da "sua" cidade, mas não que existe uma limitada zona de conforto do narrador-flâneur e que a passagem desse limite corresponde a uma retomada de perspectiva diferenciada, pelo para-brisas ou pela janela. E, para finalizar, talvez teria passado despercebido que a superação do trauma das "memórias em ruínas" faz uso, pelo menos em parte, das mesmas estratégias narrativas que o sutil discurso conservador frente às mudanças da cidade, independentemente de como se queira avaliá-las.

\section{Referências}

KRAUSZ, Luis S. (2011). Desterro: memórias em ruínas. São Paulo: Tordesilhas.

MORETTI, Franco (1999). Atlas of the European novel 1800-1900. Londres; Nova York: Verso.

PIATTI, Barbara (2008). Die Geographie der Literatur: Schauplätze, Handlungsräume, Raumphantasien. Göttingen: Wallstein.

SELIGMANN-SILVA, Márcio (2011). Posfácio: a arte de testemunhar o desterro. In: KRAUSZ, Luis S. Desterro: memórias em ruínas. São Paulo: Tordesilhas.

WESTPHAL, Bertrand (2011). Geocriticism: real and fictional spaces. Tradução de Robert T. Tally. Nova York: Palgrave Macmillan.

WINK, Georg (2015). Topografias literárias e mapas mentais: a sugestão de espaços geográficos e sociais na literatura. In: DALCASTAGNE, Regina; AZEVEDO, Luciene. Espaços possíveis na literatura brasileira contemporânea. Porto Alegre: Zouk.

Recebido em julho de 2014.

Aprovado em novembro de 2014. 


\section{resumo/abstract}

\section{Espaços ficcionalizados em Desterro, de Luis S. Krausz: um ensaio em geografia literária}

Georg Wink

A maioria dos textos ficcionais pode ser localizada geograficamente, no que diz respeito a cenário e enredo, sendo que essas localizações são concebidas de múltiplas maneiras, entre a imaginária e a realista. A partir dessa premissa óbvia, analiso o romance contemporâneo Desterro: memórias em ruínas (2011), de Luis S. Krausz, que oferece uma copiosa presença de espaços reais ficcionalizados, embora em parte históricos. Através da análise, pretendo experimentar uma metodologia particular, desenvolvida recentemente sob a denominação "geografia literária". Essa abordagem implica, primeiramente, em analisar tanto questões relevantes à relação entre texto e espaço quanto as várias formas de referenciar espaços geográficos (indicar, suprimir, anonimizar, transformar) e as funções narrativas atribuídas aos espaços ficcionalizados. Num segundo passo, e ainda de acordo com o método, os resultados serão sistematizados, comparados e apresentados por meio da geração de mapas, com o propósito de averiguar a potencialidade e as limitações da interpretação cartografada.

Palavras-chave: espaço, geografia literária, metodologia, Luis S. Krausz.

\section{Fictionalized spaces in Desterro, by Luis S. Krausz: an essay in literary geography}

Georg Wink

The majority of fictional texts can be localized geographically in terms of scenario and plot. However, these localizations are constructed in different ways, from imaginary to realistic. I will analyze the contemporary novel Desterro: memórias em ruinas (2011), by Luis S. Krausz, following this premise. The book offers a range of sophisticated representations of fictionalized real spaces, some of them representing a past that no longer exists. Through my analysis I will test a special method that has been developed recently under the name of "literary geography". This approach addresses the relevant questions of text-space relations in general, as well as the different forms of referring to geographical spaces (indicating, suppressing, anonymizing, transforming). Furthermore, different functions are attributed to the fictionalized spaces. In a second step, in line with the same method, I will test the potential of maps in providing an interpretative framework for the analysis. Possible limitations to this method will then be discussed.

Keywords: space, literary geography, literary methods, Luis S. Krausz. 